\title{
RP-HPLC Estimation of Trospium Chloride in Tablet Dosage Forms
}

\author{
M. VIJAYA LAKSHMI ${ }^{1}$, J.V.L.N.S. RAO ${ }^{2}$ AND A. LAKSHMANA RAO* \\ ${ }^{1}$ Bapatla College of Pharmacy, Bapatla- 522 101, A.P., India \\ ${ }^{2}$ A.U. College of Pharmaceutical Sciences, Visakhapatnam- 530003 , A.P., India \\ *V.V. Institute of Pharmaceutical Sciences, Gudlavalleru- 521 356, A.P., India \\ dralrao@gmail.com
}

Received 13 September 2011; Accepted 11 November 2011

\begin{abstract}
A rapid, sensitive and precise HPLC method was developed for the estimation of trospium chloride in pure and tablet dosage forms. Seperation of the drug was achieved on a reverse phase Azilent $\mathrm{C}_{18}$ column using a mobile phase consisting of phosphate buffer and acetonitrile in the ratio of $60: 40 \mathrm{v} / \mathrm{v}$. The flow rate was $1 \mathrm{ml} / \mathrm{min}$ and the detection wave length $215 \mathrm{~nm}$. The linearity was found in the range of $10-150 \mu \mathrm{g} / \mathrm{ml}$ with a correlation coefficient of 1.0000 . The proposed method was validated for its sensitivity, linearity, accuracy and precision. This method was employed for routine quality control analysis of trospium chloride in tablet dosage forms.
\end{abstract}

Keywords: Trospium chloride, Estimation, Tablets, RP-HPLC.

\section{Introduction}

Trospium chloride, (1,3,5)-3-[Hydroxy diphenyl acetyl)oxy] spiro [8 azoniabicyclo [3.2.1.] octane-8,1-pyrolidinium] chloride ${ }^{1}$ (Figure 1), is a quaternary ammonium antimuscuranic agent with actions similar to atropine. It antagonizes the effect of acetylcholine on muscarinic receptors in cholinergically innervated organs including the bladder. Its parasympatholytic action reduces the tonus of smooth muscle in the bladder. As a result, it is used for management of urinary frequency, urgency and incontinence in detrusor instablility and the elimination half-life $\mathrm{e}^{2,3}$ has been reported to be between 10 and $20 \mathrm{hrs}$. A few UV spectrophotometry ${ }^{4}$, fluorimetric ${ }^{5}, \mathrm{HPLC}^{6}, \mathrm{LC}-\mathrm{MS}^{7,8}$ methods were reported earlier for the determination of trospium chloride in biological samples. In the present study the authors report a rapid, sensitive, accurate and precise HPLC method for the estimation of trospium chloride in bulk samples and in tablet dosage forms.

\section{Experimental}

The reference sample of trospium chloride was obtained from Divya Labs, Hyderabad. HPLC grade water and acetonitrile were purchased from E.Merck (India) Ltd., Mumbai. Potassium dihydrogen phosphate and orthophosphoric acid of AR Grade were obtained from S.D. Fine Chemicals Ltd., Mumbai. 


\section{Chromatographic conditions}

The analysis of the drug was carried out on a waters HPLC system equipped with a reverse phase $\mathrm{C}_{18}$ column $(150 \times 4.6 \mathrm{~mm} ; 5 \mu \mathrm{m})$, a 2695 binary pump, an automatic injector with 20 $\mu \mathrm{L}$ injection loop and a 2487 dual absorbance detector and running on Waters empower software.

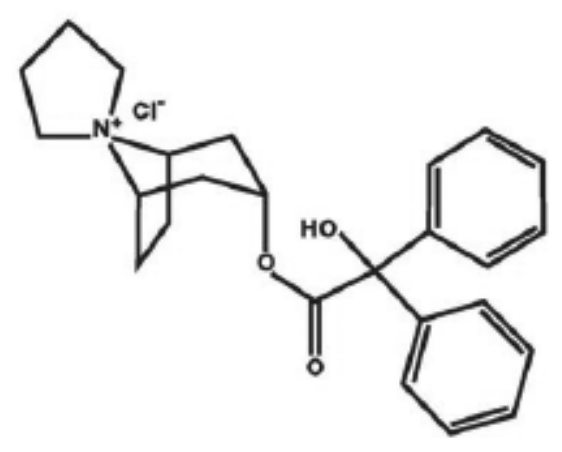

Figure 1: Chemical structure of trospium chloride.

A mixture of phosphate buffer and acetonitrile in the ratio of 60:40 v/v was found to be the most suitable mobile phase for ideal separation of trospium chloride. The solvent mixture was filtered though a $0.45 \mu$ membrane filter ad sonicated before use. It was pumped through the column at a flow rate of $1 \mathrm{ml} / \mathrm{min}$. The column was maintained at ambient temperature. The pump pressure was set at 1500 psi. The column was equilibrated by pumping the mobile phase through the column for at least 30 minutes prior to the injection of the drug solution. The detection of the drug was monitored at $215 \mathrm{~nm}$. The run time was set at $4 \mathrm{~min}$. Under these optimized chromatographic conditions the retention time obtained for the drug was $2.48 \mathrm{~min}$. A typical chromatogram showing the separation of the drug is given in Figure 2.

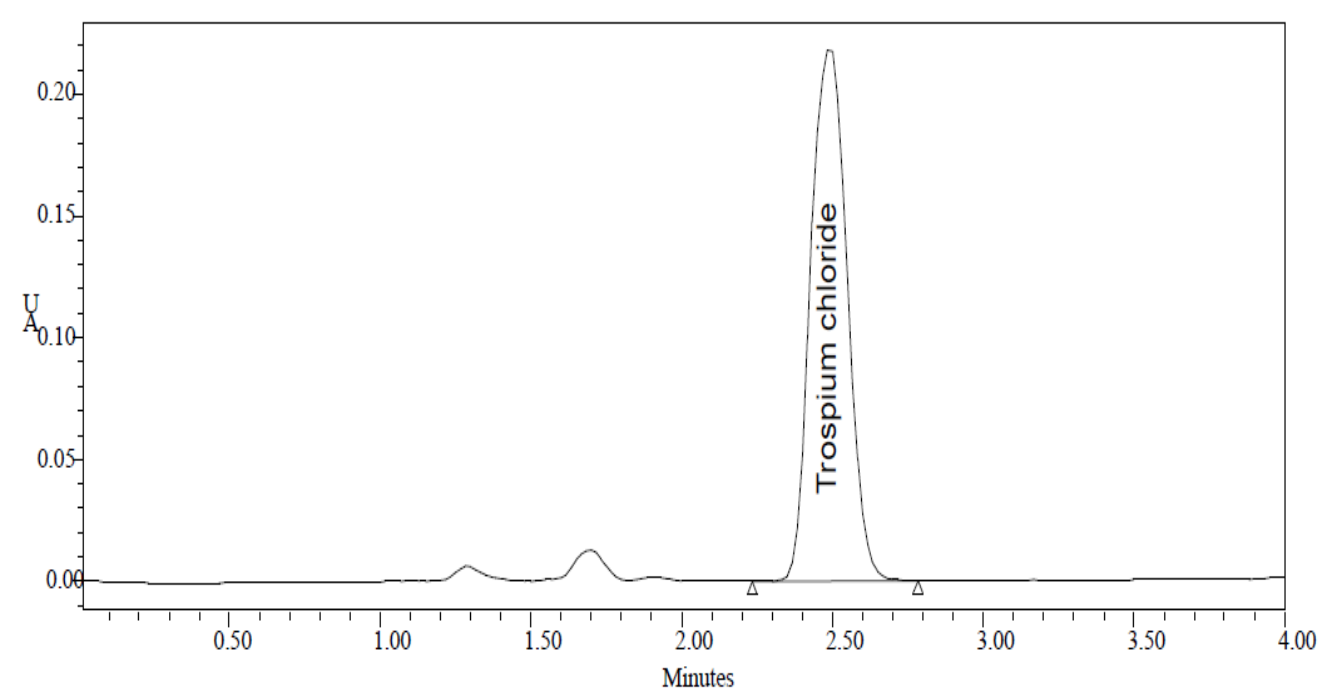

Figure 2: Typical chromatogram showing separation of trospium chloride. 


\section{Calibration plot}

About $25 \mathrm{mg}$ of trospium chloride was weighed accurately, transferred into a $100 \mathrm{ml}$ volumetric flask and dissolved $25 \mathrm{ml}$ of a $60: 40 \mathrm{v} / \mathrm{v}$ mixture of phosphate buffer and acetonitrile (Diluent) was added to the flask. The solution was sonicated for $15 \mathrm{~min}$ and the volume made up to the mark with a further quantity of the diluent to get a $250 \mu \mathrm{g} / \mathrm{ml}$ solution. From this, a working standard solution of the drug $(100 \mu \mathrm{g} / \mathrm{ml})$ was prepared by diluting $4 \mathrm{ml}$ of the above solution to $10 \mathrm{ml}$ in a volumetric flask. Further dilutions ranging from 10 to $150 \mu \mathrm{g} / \mathrm{ml}$ were prepared from the solution in $10 \mathrm{ml}$ volumetric flasks using the above diluent. $20 \mu \mathrm{l}$ of each dilution was injected six times into the column at a flow rate of $1 \mathrm{ml} / \mathrm{min}$ and the corresponding chromatograms were obtained. From these chromatograms, the average area under the peak of each dilution was computed. The calibration graph constructed by plotting concentration of the drug against peak area was found to be linear in the concentration range of $10-150 \mu \mathrm{g} / \mathrm{ml}$ of the drug. The relevant data are furnished in Table 1 . The regression equation of this curve was computed. This regression equation was later used to estimate the amount of trospium chloride in tablet dosage forms.

\section{Validation of the proposed method}

The specificity, linearity, precision, accuracy, limit of detection, limit of quantitation, robustness and system suitability parameters ${ }^{9}$ were studied systematically to validate the proposed HPLC method for the determination of trospium chloride. Solutions containing 50, 100 and $150 \mu \mathrm{g} / \mathrm{ml}$ of trospium chloride was subjected to the proposed HPLC analysis to check intra-day and inter-day variation of the method and the results are furnished in Table 2. The system suitability parameters are given in Table 3 .

Table 1: Calibration data of the method.

\begin{tabular}{ll}
\hline Concentration $(\mu \mathrm{g} / \mathrm{ml})$ & Mean peak area $(\mathrm{n}=6)$ \\
\hline 10 & 202424 \\
25 & 506052 \\
50 & 1012226 \\
75 & 1518384 \\
100 & 2024248 \\
& \\
125 & 2530300 \\
150 & 3036493 \\
\hline
\end{tabular}

Table 2: Precision of the proposed HPLC method.

\begin{tabular}{lllll}
\hline \multirow{2}{*}{$\begin{array}{c}\text { Concentration of } \\
\text { trospium chloride } \\
(\mu \mathrm{g} / \mathrm{ml})\end{array}$} & \multicolumn{3}{c}{ Measured concentration of trospium chloride $(\mu \mathrm{g} / \mathrm{ml})$} \\
\cline { 2 - 5 } & \multicolumn{3}{c}{ Intra-day } & Inter-day \\
\cline { 2 - 5 } & Mean $(\mathrm{n}=3)$ & $\%$ C.V. & Mean $(\mathrm{n}=3)$ & $\%$ C.V. \\
\hline 50 & 50.27 & 0.45 & 49.97 & 1.21 \\
100 & 99.5 & 0.69 & 99.65 & 1.81 \\
150 & 149.94 & 0.03 & 149.06 & 0.57 \\
\hline
\end{tabular}


Table 3: System suitability parameters.

\begin{tabular}{lc}
\hline Parameter & Result \\
\hline Theoretical plates $(\mathrm{N})$ & 2150 \\
Tailing Factor & 1.10 \\
Peak asymmetry & 1.2 \\
LOD $(\mu \mathrm{g} / \mathrm{ml})$ & 0.07 \\
LOQ $(\mu \mathrm{g} / \mathrm{ml})$ & 0.21 \\
\hline
\end{tabular}

\section{Estimation of trospium chloride in tablet dosage forms}

Two commercial brands of tablets were chosen for testing the suitability of the proposed method to estimate trospium chloride in tablet formulations. Twenty tablets were weighed and powdered. An accurately weighed portion of this powder equivalent to $25 \mathrm{mg}$ of trospium chloride was transferred to a $100 \mathrm{ml}$ volumetric flask and extracted with small amount of diluent. The contents of the flask were sonicated for $15 \mathrm{~min}$ and a further $25 \mathrm{ml}$ of the diluent was added, the flask was shaken continuously for $15 \mathrm{~min}$ to ensure complete solubility of the drug. The volume was made up with the diluent and the solution was filtered through a $0.45 \mu$ membrane filter. From the filtrate, $4 \mathrm{ml}$ of aliquot was taken in a separate $10 \mathrm{ml}$ volumetric flask, the contents made up to the volume. The solution was injected into the column six times. The average peak area of the drug was computed from the chromatograms and the amount of the drug present in the tablet dosage form was calculated by using the regression equation obtained for the pure drug. The relevant results are furnished in Table 4.

Table 4: Recovery from dosage forms.

\begin{tabular}{llll}
\hline Formulation & Label claim $(\mathrm{mg})$ & Amount found $(\mathrm{mg})(\mathrm{n}=6)$ & \% Amount found \\
\hline Brand-1 & 20 & 19.80 & 99.00 \\
\hline Brand-2 & 60 & 59.86 & 99.77 \\
\hline
\end{tabular}

\section{Results and Discussion}

In the proposed method, the retention time of trospium chloride was found to be $2.48 \mathrm{~min}$. Quantification was linear in the concentration range of $10-150 \mu \mathrm{g} / \mathrm{ml}$. The regression equation of the linearity plot of concentration of trospium chloride over its peak area was found to be $Y=20243 X+43.07(r=1.0000)$, where $X$ is the concentration of trospium chloride $(\mu \mathrm{g} / \mathrm{ml})$ and $\mathrm{Y}$ is the corresponding peak area. The number of theoretical plates calculated was 2150, which indicates efficient performance of the column. The limit of detection and limit of quantitation were found to be $0.07 \mu \mathrm{g} / \mathrm{ml}$ and $0.21 \mu \mathrm{g} / \mathrm{ml}$ respectively, which indicate the sensitivity of the method. The use of phosphate buffer and acetonitrile in the ratio of 60:40 v/v resulted in peak with good shape and resolution. The high percentage of recovery indicates that the proposed method is highly accurate. No interfering peaks were found in the chromatogram within the run time indicating that excipients used in tablet formulations did not interfere with the estimation of the drug by proposed HPLC method. 


\section{Conclusion}

The proposed HPLC method is rapid, sensitive, precise and accurate for the determination of trospium chloride and can be reliably adopted for routine quality control analysis of trospium chloride in its tablet dosage forms.

\section{Acknowledgements}

The authors are thankful to M/s Divya Labs Ltd., Hyderabad for providing a reference sample of trospium chloride.

\section{References}

1. S. Budavari., Eds., In; The Merck Index; $13^{\text {th }}$ Edn., Merck \& Co., Inc., Whitehouse Station, NJ, 2004, p. 9857.

2. www.rxlist.com

3. Doroshyenko O, Jetter A, Odenthal K P, Fuhr U, Clinical Pharmacokinetics, 2005, 44(7), 701-720.

4. Bendale A R, Vijaykumar P S, Sushil P N, Sachin B N, Anil G J, Vidyasagar G, Indo Global Journal of Pharmaceutical Sciences, 2011, 1(2), 166-172.

5. Schladitz-Keil G, Spahn H, Mutschler E, Journal of Chromatography B, 1985, 345, 99-110.

6. Hong X, Jinsong L D, Zhirong T, Ping G, Yang, Chinese Journal of Hospital Pharmacy, 2007, 27(4), 451.

7. Kishore Kumar H, Vijaya Bharathi D, Sirish Kumar S, Narasimha Reddy Y, Chatki P K, Ravindranath L K, Jayaveera K N, Journal of Chromatography B, 2010, 878, 981986.

8. Tang J, Tan Z R, Zhou Y B, Ding J S, Analytical Letters, 2011, 44(4), 607-616.

9. Validation of analytical procedures: Text and Methodology, ICH Hormonised Tripartite Guideline Q2 (R1), Commission of the European Communities, 2005. 


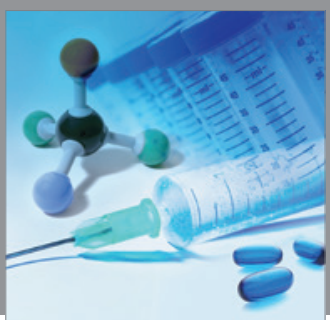

International Journal of

Medicinal Chemistry

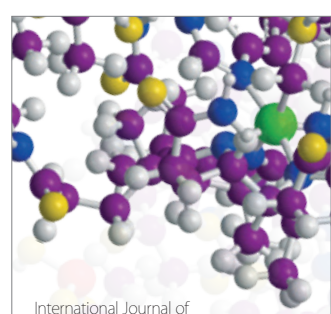

Carbohydrate Chemistry

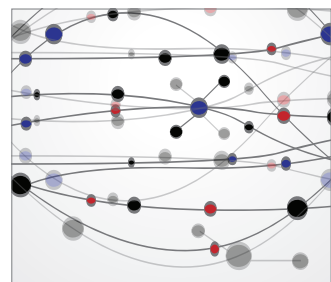

The Scientific World Journal
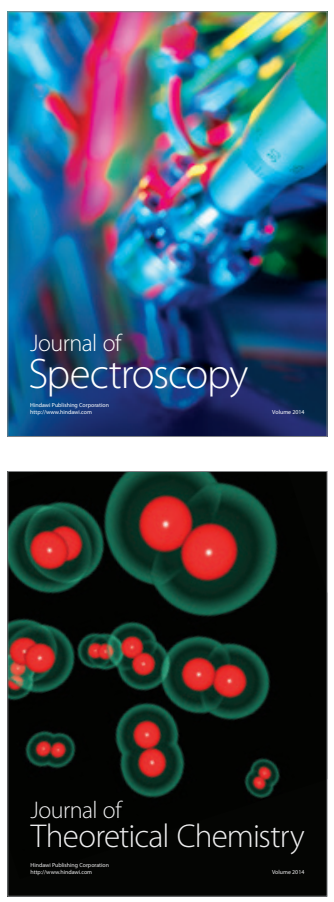
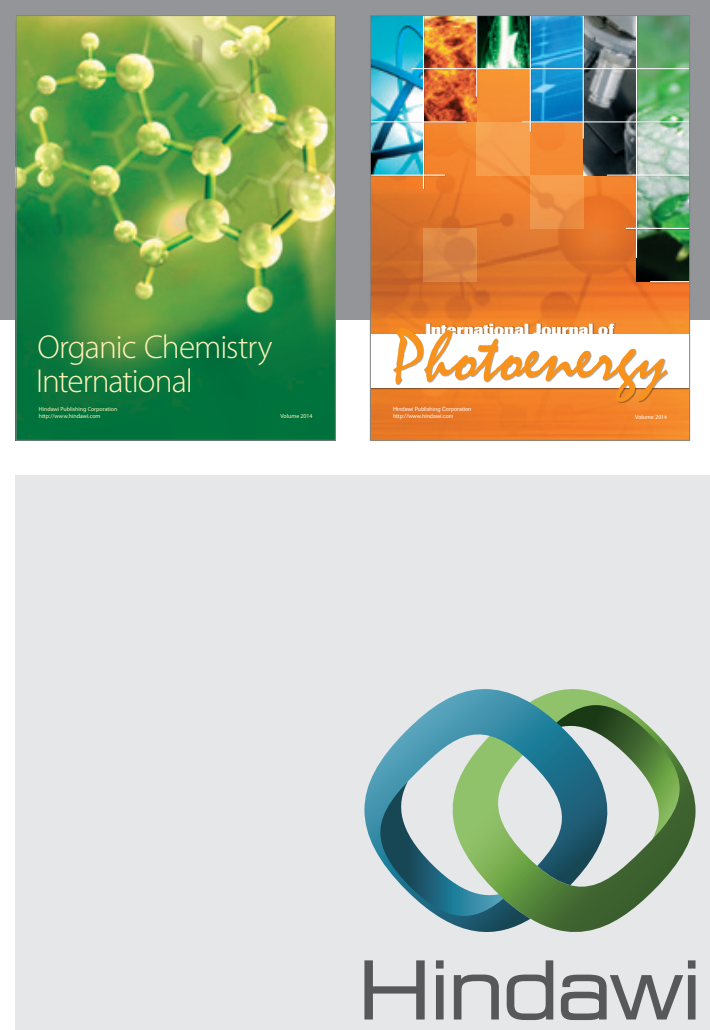

Submit your manuscripts at

http://www.hindawi.com
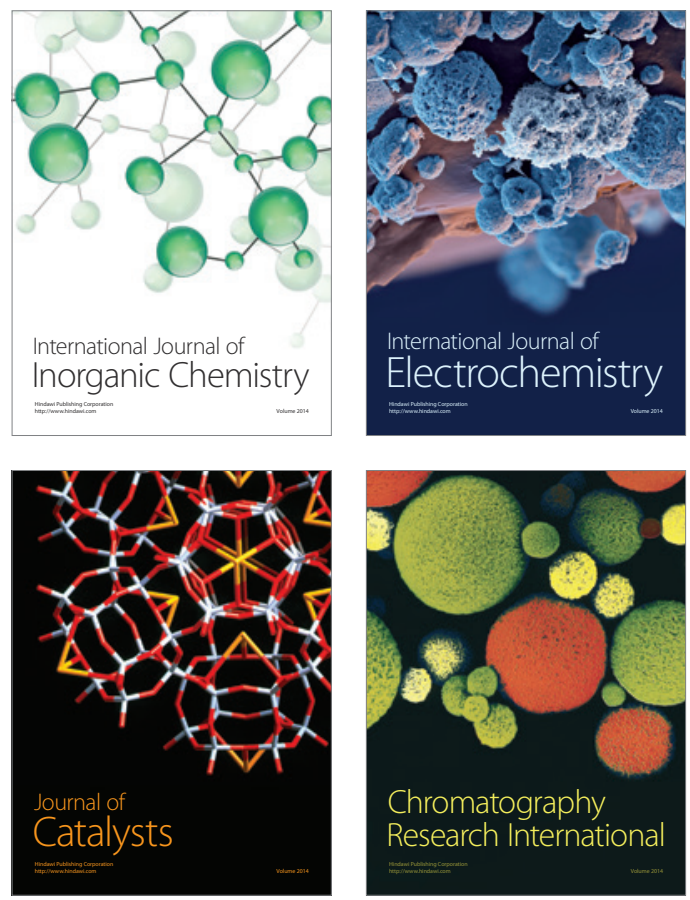
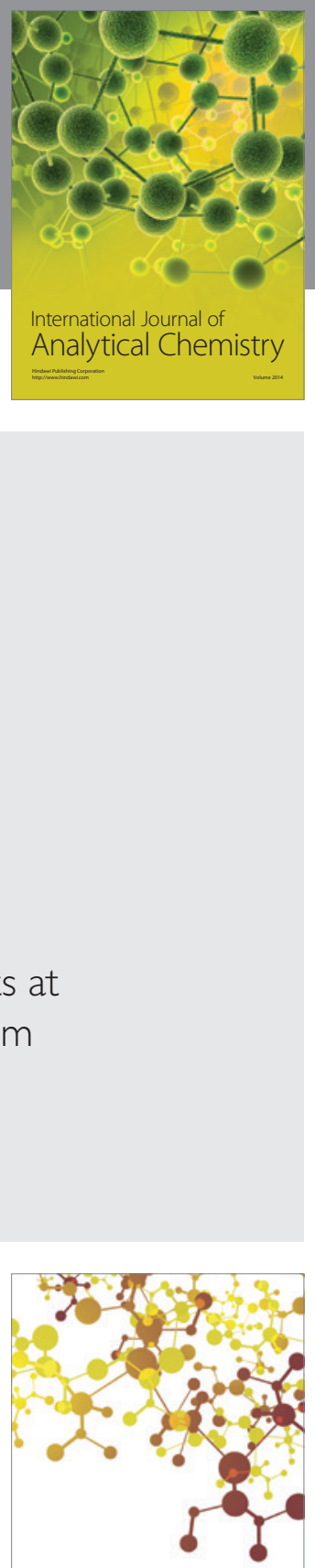

Journal of

Applied Chemistry
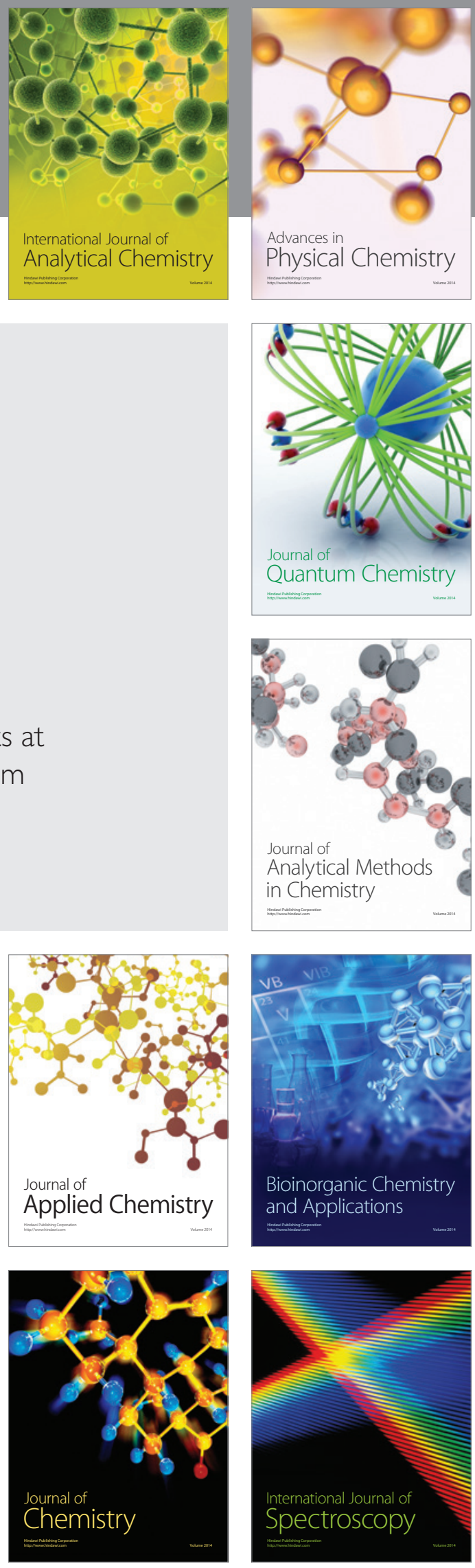